\title{
OnabotulinumtoxinA for the treatment of overactive bladder
}

This article was published in the following Dove Press journal:

Research and Reports in Urology

2I July 2014

Number of times this article has been viewed

\section{Lindsey Cox \\ Anne P Cameron}

Department of Urology, University of Michigan, Ann Arbor, MI, USA
Correspondence: Lindsey Cox Department of Urology, University of Michigan, 1500 E Medical Center Drive, 3875 Taubman Center, SPC 5330, Ann Arbor, MI 48109-5330, USA

$\mathrm{Tel}+\mathrm{I} 734232488$ I

$\mathrm{Fax}+\mathrm{I} 7349369127$

Email Imenchen@med.umich.edu
Abstract: OnabotulinumtoxinA injection is a safe and effective treatment for adults with refractory overactive bladder. There is sufficient level 1 evidence to support offering onabotulinumtoxinA injections as a second-line treatment to patients who have failed behavioral therapy and oral medications such as antimuscarinics and $\beta 3$ agonists. An intradetrusor injection of $100 \mathrm{U}$ of onabotulinumtoxinA is likely the optimal dose to balance risks and benefits, and this is the dose approved by the US Food and Drug Administration. Improvement in urgency urinary incontinence episodes, as well as symptom scores and quality of life, were seen in around $60 \%-65 \%$ of patients, and were significantly improved compared with those on placebo. Most studies have reported a duration of symptom relief ranging from 6 to 12 months, with repeat injections being safe and efficacious. Overall, the risk of urinary retention was around $6 \%$ across the study populations.

Keywords: urgency urinary incontinence, urinary retention, nocturia, frequency

\section{Introduction}

"Overactive bladder" (OAB) is defined as a syndrome of urinary urgency, usually accompanied by frequency and nocturia, with or without urgency urinary incontinence, in the absence of urinary tract infection (UTI) or other obvious pathology. ${ }^{1}$ It is very common in the general population, affecting $\sim 16 \%$ of both men and women, with prevalence increasing with age. ${ }^{2}$ Its most bothersome symptom, urgency incontinence, is roughly twice as common in women than in men $(2.0 \%-19.0 \%$ vs $0.3 \%-8.9 \%)$, with a marked increase after the age of 44 in women and after 64 in men. There are many theories behind the etiology of OAB, but it is generally accepted that it caused by a combination of myogenic and neurogenic alterations. ${ }^{3}$ It is also believed that mucosal sensory systems make a significant contribution to the disorder as well. ${ }^{4}$

Initial conservative treatment options for OAB include timed voiding, fluid- and food-irritant management, bladder retraining, and pelvic-floor physical therapy. ${ }^{5}$ If these are unsuccessful, first-line pharmacologic therapy is with antimuscarinics (eg, oxybutynin, tolterodine, trospium) or $\beta 3$ agonists (mirabegron). ${ }^{6}$ Unfortunately, only rarely do patients with urgency incontinence achieve complete cure of their incontinence with conservative management and/or medications, and most trials report only reduction in episodes of leakage. ${ }^{7}$ Side effects of antimuscarinics such as dry mouth and constipation are all too common and very bothersome to patients. In a community setting, after 2 years, only $6 \%-12 \%$ of patients prescribed antimuscarinics for OAB continue to take their prescriptions, ${ }^{8}$ and these drop outs are mostly due to lack of efficacy. ${ }^{9}$ Adrenergic $\beta 3$ agonists have recently been approved by the US Food 
and Drug Administration (FDA); hence, post-market studies on adherence are not currently available. Beta-3 agonists do have a better side-effect profile than antimuscarinics, with no dry mouth or constipation, and efficacy appears to be similar to that of extended-release antimuscarinics. ${ }^{10}$

Patients who are either intolerant of medical therapy or have failed medical therapy are considered to have "refractory overactive bladder" (ROAB). There is no requisite number of medications attempted for their disorder to be considered ROAB and no formal definition of this syndrome, ${ }^{11}$ but for those patients without contraindications to medical therapy, it is reasonable as a first step in a patient who has failed one medication to simply switch to an alternative medication. Occasionally, patients do respond to these maneuvers, particularly when the reason for failure is side effects. The efficacy of all the extended-release anticholinergics is similar; ${ }^{7}$ however, the side-effect profiles are of different severity, so altering therapy to avoid side effects can be very effective. It is rare for a patient to fail three medications and suddenly respond to therapy with a fourth. It is important to not get stuck at this step in the path of treatment and needlessly leave a patient with inadequate treatment for their OAB.

There are three FDA-approved second-line therapies available for patients with ROAB. Sacral neuromodulation (SNM) was FDA approved for urgency incontinence and urgency/frequency syndrome in 2007. It is very effective, with low explantation rates; however, the nature of the implantable device necessitates its replacement and revision surgery is very common. ${ }^{12}$ Also, not all patients are able or willing to have a metal implantable device inserted. Percutaneous tibial nerve stimulation was FDA approved in 2010 for $\mathrm{OAB}$ and is a minimally invasive technique utilizing electrical stimulation of the tibial nerve via a 34-gauge needle. The technique has a very low risk of adverse events but requires weekly office visits for 12 weeks followed by maintenance therapy, which is not always convenient for patients. ${ }^{13}$ Botulinum toxin bladder injections have been used off-label for many years and were FDA approved for neurogenic bladder in 2011 and for urgency incontinence in 2013. To date, as far as we are aware, there are no published trials on the comparative efficacy of these three therapies; however, an ongoing randomized trial - Refractory Overactive Bladder: Sacral Neuromodulation v BoTulinum Toxin Assessment (ROSETTA) (NCT01502956) - aims to compare SNM with onabotulinumtoxinA for women with refractory urgency incontinence and preliminary results are expected in this year (2014).
There are seven serotypes of botulinum toxin $(A-G)$ with botulinum toxin type $\mathrm{A}$ being the most commonly utilized to treat lower urinary tract symptoms. There are several proprietary preparations of the protein that are produced via different methods, and, as all contain different fragments of the protein, the dose, efficacy, and safety profiles are not the same. ${ }^{14}$ The two most studied preparations are onabotulinumtoxinA (Botox ${ }^{\mathrm{TM}}$, Allergan, Inc., Irvine, CA, USA) and abobotulinumtoxinA (Dysport ${ }^{\circledR}$, Ipsen Biopharm Ltd, Slough, UK). ${ }^{14}$ There is also no reliable conversion dosing that can be utilized. ${ }^{15}$ This was shown in a prospective database from Nottingham, UK: the institution switched from Botox to Dysport ${ }^{\circledR}$ in 2009 and evaluated the comparative efficacy and complications in a group of 207 patients with OAB. They utilized a conversion ratio of 2.5:1.0 (Dysport ${ }^{\circledR}$ : Botox) in deciding on injection dose. The reduction in frequency, nocturia, and incontinence was similar between groups, but the rate of symptomatic retention requiring clean intermittent self-catheterization (CIC) was doubled in the Dysport group (23\% vs $42 \%$ ). The only FDA-approved agent for bladder injection for OAB is Botox, hence, unless specified, all studies discussed in this paper hereafter refer to the onabotulinumtoxinA (Botox) preparation. ${ }^{15}$

OnabotulinumtoxinA affects the nerve terminals in the bladder and in all other muscles by cleaving the SNAP25 protein that is part of the SNARE complex attachment protein. The SNARE protein is rendered inactive, and its associated synaptic vesicles can no longer fuse with the cytoplasmic membrane. These synaptic vesicles are responsible for acetylcholine (ACh) release from motor nerves in striated muscle and in the bladder. SNAP25 expression has been observed in parasympathetic, sympathetic, and sensory nerves, explaining its effects on both detrusor contractions and urgency. OnabotulinumtoxinA also appears to influence urothelial function, causing inhibition of adenosine triphosphate release - at least in animal models. ${ }^{16}$

\section{Results for onabotulinumtoxinA in OAB}

Basic science research on the effects of botulinum toxin in animals and humans has shed a great deal of light on the mechanism of action of botulinum toxin in the bladder and symptom relief in idiopathic OAB. In striated muscle, botulinum toxin leads to flaccid paralysis, because the ACh from cholinergic motor-nerve endings is not released to excite the muscle. Direct correlation of this mechanism to the bladder would be an oversimplification, and the complex mechanisms that may be at work have been studied in animals and 
humans with the caveat that the sensation of urgency itself is not completely understood. ${ }^{17}$

Collins et al tested the hypothesis that onabotulinumtoxinA does not simply block parasympathetic efferent ACh release to inhibit detrusor contraction in humans but also has afferent effects. ${ }^{18}$ In an in vitro murine model, bladder afferent nerve activity was recorded simultaneously with intravesical pressure while the bladder was distended. They reported that intraluminal onabotulinumtoxin A inhibited adenosine triphosphate release from the urothelium and increased nitricoxide release from the urothelium but did not affect $\mathrm{ACh}$ release from the urothelium, as it is not contained in vesicles in this location. This resulted in an attenuated response to distention in low- and high-threshold afferent nerve units.

Reports of the use of onabotulinumtoxin A in OAB followed soon after trials of intravesical injection of the toxin in the neurogenic bladder population. Smaller early placebo-controlled randomized clinical trials demonstrated the clinical and urodynamic efficacy of onabotulinumtoxin $A$ at various doses in the OAB population. ${ }^{19,20}$ As far as the onset of symptom relief, studies have shown that OAB patients note significant changes in sensation of urgency, frequency, and urgency incontinence starting at day 3-4, with improvements in nocturia lagging behind until after the first week but showing significant improvement thereafter. ${ }^{20,21}$

Brubaker et al reported the results of an early randomized, placebo-controlled, double-blind trial with 43 women affected by $\mathrm{OAB}$ who received either placebo or $200 \mathrm{U}$ onabotulinumtoxinA. ${ }^{22}$ The study was designed for sample size of 210 subjects but was placed on clinical hold because an interim analysis revealed an unacceptable level of incomplete bladder emptying. The median duration of response was 373 days for onabotulinumtoxinA and 62 days for placebo. Of the women who received onabotulinumtoxinA, $60 \%$ had a clinical response based on Patient Global Impression of Improvement 1 month after injection, and a 75\% improvement in incontinence occurred in $72 \%$ of patients receiving onabotulinumtoxinA and $0 \%$ of patients receiving placebo $(P<0.0001)$. Although it was not completed, these results suggest a high rate of efficacy in this population. Additionally, the authors reported that the need for catheterization did not degrade the perception of efficacy of the treatment, as the patients on intermittent catheterization did not have lower PGI-I scores.

Contemporary larger-scale randomized-controlled trials (RCTs) have evaluated onabotulinumtoxinA in a more controlled fashion. Starting with Phase II dose-ranging studies and ending with two large-scale Phase III studies, these trials together provide strong level 1 evidence for the efficacy of $100 \mathrm{U}$ onabotulinumtoxinA injections for OAB. Dmochowski et $\mathrm{al}^{23}$ reported on a Phase II, multicenter, double-blind, dose-ranging trial in 2010. A total of 313 patients with $\mathrm{OAB},>8$ micturitions per day, and eight or more urgencyincontinence episodes per week were administered $50 \mathrm{U}$, $100 \mathrm{U}, 150 \mathrm{U}, 200 \mathrm{U}$, or $300 \mathrm{U}$ of onabotulinumtoxinA or placebo. Results were reported at 12 weeks and showed that all doses of $100 \mathrm{U}$ or greater showed improvement over placebo for the primary outcome of reduction of weekly urgency incontinence episodes. Further analysis of the doseresponse curve of the cumulative effect of the various doses showed that doses $>150 \mathrm{U}$ did not provide demonstrable additional improvement in this outcome. The authors noted that both increases in post-void residual urine volume and use of intermittent catheterization were dose dependent and, therefore, suggested $100 \mathrm{U}$ as the dose in OAB that best balances benefits with safety.

In 2012, Denys et al described the results of a randomized, placebo-controlled, double-blind, dose-ranging study in France. ${ }^{24}$ Patients with refractory OAB and urodynamically proven detrusor overactivity were randomized to receive onabotulinumtoxinA at $50 \mathrm{U}, 100 \mathrm{U}$, or $150 \mathrm{U}$, or placebo. The study did not reach its enrollment goal of 160 patients and was underpowered, reportedly due to slow recruitment. The results of the interim analysis of 99 patients at 3 months showed that $42 \%$ of those receiving $100 \mathrm{U}$ and $42 \%$ of patients receiving $150 \mathrm{U}$ met criteria for a $>75 \%$ reduction in symptoms from baseline, which reached significance. The $50 \mathrm{U}$ dose did not show a difference from placebo. Significant changes from baseline in urodynamic parameters of voided volume, volume at first contraction, and strong desire to void, as well as maximum cystometric capacity were shown at 3 months for the $150 \mathrm{U}$ dose, with only voided volume and volume at first contraction showing significance for the $100 \mathrm{U}$ dose. Qualityof-life measures showed sustained improvement for the 100 $\mathrm{U}$ and $150 \mathrm{U}$ doses that remained significant up to 6 months after injection. The authors concluded that the $100 \mathrm{U}$ dose is likely to be optimal but that further studies will be needed to determine differences in the $150 \mathrm{U}$ and $100 \mathrm{U}$ doses.

Tincello and colleagues published the results of the RELAX study in $2012 .{ }^{25}$ The randomized, placebo-controlled, double-blind trial enrolled 240 women with refractory OAB to compare $200 \mathrm{U}$ onabotulinumtoxinA and placebo injection. At 6 months, the primary outcome of voiding frequency per 24 hours was significantly reduced in patients receiving onabotulinumtoxinA injections compared with those receiving placebo (difference of 1.33 voids). Secondary outcomes 
of quality-of-life scores and incontinence episodes per 24 hours were markedly reduced (difference of 4.33 episodes) in the treatment group.

Chapple et al reported the results of a large, Phase III, multicenter, randomized, placebo-controlled, double-blind trial of injection of $100 \mathrm{U}$ of onabotulinumtoxinA versus placebo for OAB in $2013 .{ }^{26} \mathrm{~A}$ total of 277 patients received $100 \mathrm{U}$ onabotulinumtoxinA and reported a reduction in urgency incontinence episodes of 2.95 per day, compared with a reduction of 1.03 episodes in the 271 patients who received placebo $(P<0.001)$. The results for a positive response on the treatment benefit scale of "greatly improved" or "improved" were also highly significant, in that $62.8 \%$ of patients receiving onabotulinumtoxinA reported a positive response in comparison to $26.8 \%$ of patients receiving placebo $(P<0.001)$.
A similar Phase III multicenter study by Nitti et al compared injection of $100 \mathrm{U}$ of onabotulinumtoxinA to placebo in 557 patients with OAB. ${ }^{27}$ OnabotulinumtoxinA injection resulted in a reduction of 2.65 episodes of incontinence per day compared with 0.87 for placebo $(P<0.00)$ at week 12 . Treatment benefit scale responses were $60.8 \%$ positive for onabotulinumtoxinA vs $29.2 \%$ positive for placebo $(P<0.001)$. A summary of efficacy data for all RCTs is presented in Table 1.

Various investigators have tried to predict treatment success based on patient factors. In 2008, White et al investigated the use of onabotulinumtoxinA in the elderly in a small study of 21 patients aged 75 or older (mean age 81.2 years). ${ }^{28}$ They found that after a single $200 \mathrm{U}$ intradetrusor injection, 16/21 patients showed a clinical response, and, after

Table I Outcomes of placebo-controlled trials

\begin{tabular}{|c|c|c|c|c|}
\hline $\begin{array}{l}\text { Study (time point of reporting) } \\
\text { Dose (N) }\end{array}$ & $\begin{array}{l}\text { Urgency incontinence } \\
\text { episodes }\end{array}$ & Urgency & Symptom scores & $\begin{array}{l}\text { Patient-reported } \\
\text { measures }\end{array}$ \\
\hline Chapple et al' ${ }^{26}$ (week I2) & Change in IE/day & Change in urgency/day & & Positive response on TBS \\
\hline $100 \cup(277)$ & $-2.95(P<0.001)$ & $-2.95(P<0.001)$ & & $62.8 \%(P<0.001)$ \\
\hline Placebo (27I) & -1.03 & -1.24 & & $26.8 \%$ \\
\hline Nitti et al ${ }^{27}$ (week 12) & Change in IE/day & Change in urgency/day & & Positive response on TBS \\
\hline $100 \cup(280)$ & $-2.65(P<0.001)$ & $-2.93(P<0.001)$ & & $60.8 \%(P<0.001)$ \\
\hline Placebo (277) & -0.87 & -1.21 & & $29.2 \%$ \\
\hline Denys et al ${ }^{24}$ (month 3 ) & & & & $>75 \%$ reduction in symptoms \\
\hline $50 \cup(2 I)$ & & & & $6 \%$ \\
\hline $100 \cup(22)$ & & & & $42 \%(P=0.03)$ \\
\hline $150 \cup(27)$ & & & & $42 \%(P=0.03)$ \\
\hline Placebo (29) & & & & $22 \%$ \\
\hline Dmochowski et al ${ }^{23}$ (week I2) & Proportion IE free & & & \\
\hline $50 \cup(57)$ & $29.8 \%$ & & & \\
\hline $100 \cup(54)$ & $37.0 \%$ & & & \\
\hline $150 \cup(49)$ & $40.8 \%$ & & & \\
\hline $200 \cup(53)$ & $50.9 \%$ & & & \\
\hline $300 \cup(56)$ & $57.1 \%$ & & & \\
\hline Placebo (44) & $15.9 \%$ & & & \\
\hline Tincello et $\mathrm{a}^{25}$ (month 6) & $\mathrm{IE} /$ day & Urgency/day & Urgency severity score & IQOL \\
\hline $200 \cup(122)$ & $\mathrm{I} .67(P=0.000 \mathrm{I})$ & $3.83(P<0.0001)$ & $1.50(P=0.0006)$ & $55.1 \mathrm{I}(P<0.000$ I) \\
\hline Placebo (I I8) & 6.0 & 6.33 & 1.9 & 27.27 \\
\hline Brubaker et a ${ }^{22}$ (day 60 [clinical hold]) & $75 \%$ reduction & & UDI-urge subscale & PGI-I score \\
\hline $200 \cup(28)$ & $72 \% *$ & & $31(P=0.003)$ & $2.7(P=0.003)$ \\
\hline Placebo (15) & $0 \%$ & & 52 & 4.0 \\
\hline Sahai et $\mathrm{al}^{20}$ (week I2) & Change in IE/day & & Difference in UDI-6 & Difference in IIQ-7 \\
\hline $200 \cup(16)$ & $-3.50(P<0.0076)$ & & $-5.13(P<0.0001)$ & $-10.38(P=0.0063)$ \\
\hline Placebo (18) & $-0.7 \mathrm{I}$ & & +0.5 & $+0.6 \mathrm{I}$ \\
\hline Flynn 19 (week 6) & Change in IE/day & & Difference in UDI & Difference in IIQ \\
\hline $200 \cup$ or $300 \cup(15)$ & $-4.5(P<0.0 \mathrm{I})$ & & $-18.6(P=0.04)$ & $-39.5(P=0.02)$ \\
\hline Placebo (7) & +0.7 & & +3.1 & 0 \\
\hline
\end{tabular}

Note: $* P$-value $<0.0001$.

Abbreviations: IE, incontinence episodes; IIQ, Incontinence Impact Questionnaire; IQOL, incontinence quality of life; PGI, Patient global impression of improvement; TBS, Treatment Benefit scale; UDI, Urinary Distress Inventory scale. 
a second injection 3 months later, two of the five failures showed a demonstrable response. This study suggests that onabotulinumtoxinA injection in selected elderly patients with idiopathic OAB without detrusor underactivity or elevated post-void residual (PVR) at baseline is safe and effective.

In 2011, Kuo published a large retrospective analysis looking at efficacy based on sensory or motor response to $100 \mathrm{U}$ injection of onobotulinumtoxinA.$^{29}$ The report focused on subgroups of their previous 174 trial participants grouped according to those who had a sensory response, measured as change in Urgency Severity Scale; those who had a motor response, measured as an increase in cystometric capacity of $25 \%$ or more; those who had neither; and those who had both. All of the patients (100\%) with sensory effects, with or without motor effects, reported successful outcomes, whereas only $60 \%$ of the patients with motor effects alone reported success. They also noted a correlation between sensory effects, with or without motor effects, and therapeutic duration, with longer duration in patients with sensory effects.

Another retrospective study investigated predictors of efficacy of the first onabotulinumtoxinA injection in $\mathrm{OAB}$ based on reasons for discontinuation of antimuscarinic medications. ${ }^{30}$ Their data suggest that patients who simply cannot tolerate antimuscarinics, instead of those who have truly refractory symptoms, may have a more easily treated condition and enjoy a higher rate of success.

\section{Injection technique}

American Urological Association guidelines recommend the use of prophylactic antibiotics for cystoscopy with manipulation for all patients. ${ }^{31}$ Most studies administered antibiotics, although the protocols ranged from a single dose through to use up to 3 days before to 3 days after injection. Urinalysis to exclude active infection in patients on the day of the procedure is routine, and microscopy can be done immediately by the provider in office for equivocal results. Studies also vary in the use of sedation and the protocol for local anesthetic administration. Most often, it was the provider and patient's shared decision of whether to sedate or utilize local anesthetic only. One trial reported similar pain scores of $\sim 4 / 10$ on a visual analog scale for subjects that had either local or general anesthetic. ${ }^{24}$ Intravesical premedication can be given in the office with $40 \mathrm{~mL}$ of $2 \%$ lidocaine instilled via catheter into the bladder for a dwell time of 20 minutes prior to injection, with care taken to drain the medication before the injection.

The choice of cystoscopic instrument used for injection is based on surgeon preference, patient anatomy (urethral and body positioning), and the resources available. It is preferable to have the camera, light source, light cord, and injection supplies verified to be in working order prior to reconstituting the medication to avoid a costly discard of the toxin. The benefits for ease of injection and visualization for rigid cystoscopy are balanced with the need for lithotomy positioning and discomfort. Many institutions use a rigid cystoscope with local anesthetic for females and for anesthetized males. Flexible cystoscopy can be performed with local anesthetic in the supine position in men or in the frog-leg position for women; however, we have anecdotally found that both setup and injection are simplified by having all patients in the lithotomy position if possible. A summary of the available needles for injection, with sizing for scope compatibility, can be found in Table 2 .

Patients should be given adequate post-procedure instructions in written and verbal form and should be educated about the warning signs for UTI and urinary retention.

The Botox package insert recommends $100 \mathrm{U}$, as $0.5 \mathrm{~mL}$ (5 U) injections across 20 sites into the detrusor, for a total volume of $10 \mathrm{cc}$, but, across studies, the concentration of toxin and volume of fluid that is injected is not consistent.

Table 2 Available injection needles

\begin{tabular}{|c|c|c|c|c|}
\hline Cystoscope & Supplier (part number/s) & $\begin{array}{l}\text { French (F) size/ } \\
\text { length, } \mathrm{cm}\end{array}$ & $\begin{array}{l}\text { Needle } \\
\text { gauge }\end{array}$ & $\begin{array}{l}\text { Needle tip } \\
\text { length, } \mathrm{mm}\end{array}$ \\
\hline \multirow[t]{4}{*}{ Flexible } & Coloplast (NBII070) & $5 F / 70$ & $22 \mathrm{G}$ & 4 \\
\hline & Cook (G56487) & $6 \mathrm{~F} / 70$ & $23 \mathrm{G}$ & 4 \\
\hline & Laborie (DIS20O) & $6 \mathrm{~F} / 70$ & $23 \mathrm{G}$ & Adjustable 2, 3, 5 \\
\hline & Olympus (NM-I0IC-0427; MAJ565; MAJ-655) & $6 \mathrm{~F} / 105$ & $27 \mathrm{G}$ & 4 \\
\hline \multirow[t]{7}{*}{ Rigid } & Coloplast (NBI035) & $5 F / 35$ & $22 \mathrm{G}$ & 4 \\
\hline & Cook (GI4220) & $3.75 F / 35$ & $23 \mathrm{G}$ & 8 \\
\hline & Cook (GI6II2) & $3.75 F / 45$ & $23 \mathrm{G}$ & 8 \\
\hline & Cook (GI5276) & $3.75 F / 35$ & $25 \mathrm{G}$ & 8 \\
\hline & Laborie (DISI98) & $6 F / 35$ & $25 \mathrm{G}$ & Adjustable 2, 3, 5 \\
\hline & Olympus/Gyrus ACMI (EAWE-N) & $6 \mathrm{~F}$ & & \\
\hline & Wolf (8652.775) & $3 F / 31.3$ & $22 \mathrm{G}$ & 6 \\
\hline
\end{tabular}

Notes: Coloplast, Minneapolis, MN, USA; Cook, Bloomington, IN, USA; Laborie, Toronto, Canada; Olympus, Center Valley, PA, USA; Wolf, Vernon Hills, IL, USA. 
The larger contemporary clinical trials diluted each $100 \mathrm{U}$ in $10 \mathrm{cc}$; however, studies range from $300 \mathrm{U}$ in $3 \mathrm{cc}$ to $100 \mathrm{U}$ in 20 cc. "Botox" is a vacuum-dried protein available in 50, 100, and $200 \mathrm{U}$ vials that must be refrigerated. Before injection, the vials of toxin must be reconstituted with preservative-free saline and the mixture can be stored at $2^{\circ} \mathrm{C}-8^{\circ} \mathrm{C}$ for up to 24 hours. Of note, the product does contain human albumin, which should be disclosed due to the reluctance of some patients to receive this. ${ }^{15}$ When preparing the mixture, avoid vigorous shaking of the vial to prevent protein denaturation. It is an important practical consideration to develop an institutional system for labeling the syringes that contain botulinum toxin dilutions, especially if nurses or other staff are involved in preparing the solutions.

Injection technique also varies across the studies of onabotulinumtoxinA, including the location of injections, the depth of injections, the number of injection sites, and the volume at each site. Kuo retrospectively studied injection location and found that success rates did not change based on location in the bladder body alone versus trigone alone or bladder body and trigone. ${ }^{32}$ Trigone injections have not been shown to be associated with the development of vesicoureteral reflux. The number of injections has varied in studies from 12 to 40, but was typically in the range of 15-20 sites. The depth of injection is also variable, and does depend somewhat on the length of the needle tip used for injections. It is likely that there is some variability even with the same surgeon, and there have been no findings that have determined superiority of sub-urothelial versus intradetrusor injection. Intra-detrusor injections should be performed when the bladder is moderately full. As a teaching tool, some studies included a tiny amount of indigo carmine or methylene blue to the injection solution to facilitate standardization and visualization of one's injection pattern. A video of injection technique can be found at https:// www.youtube.com/watch? $\mathrm{v}=\mathrm{ds} 1 \mathrm{SOH} 7 \mathrm{qQxo}$.

\section{Repeat injections}

Retrospective studies have also helped to illustrate the duration of efficacy of onabotulinumtoxinA, especially after the first injection. Reports of the initial period of symptom relief range from 6.3 to 10.6 months..$^{21,28-30,33}$ Studies of repeat injections give insight into the therapeutic duration of injections over time, as well as changes in efficacy over multiple injections. Frequency of repeat injections in studies ranged from 12 weeks to almost 1.5 years. ${ }^{34,35}$ Sahai et al published a small series of 20 patients who were injected more than once, and they reported that the median time between injections 1 and 2, injections 2 and 3, and injections 3 and 4 was 377, 378, and 256 days, respectively, noting a shortening of the duration. ${ }^{34}$ A nonrandomized, open-label prospective cohort studied 81 consecutive patients with ROAB over a mean follow-up of 2.8 years (range $0.3-5.7) .{ }^{35}$ The inter-injection interval was $12-15$ months, and quality-of-life improvement was also sustained after each injection.

Granese et al reported on 68 women with ROAB who received $100 \mathrm{U}$ of onabotulinumtoxinA. ${ }^{36} \mathrm{~A}$ total of 25 women reported symptom return, 20 of whom underwent a second injection. They reported a mean inter-injection interval of 12 months, noting an average duration of objective (urodynamic) efficacy of 9 months; both urodynamic and symptom parameters showed persistent improvement at 3 months after the second injection. In 2011, Gamé et al examined the effect of repeat injections on health-related quality of life in an open-label study. ${ }^{37}$ In 42 patients receiving $200 \mathrm{U}$ of onabotulinumtoxinA, the mean inter-injection interval was 17.1 months. The Urinary Distress Inventory 6 (UDI-6) and Incontinence Impact Questionnaire (IIQ-7) showed consistent improvement before and after injections up to the reported fifth injection, indicating that efficacy was maintained. Dowson et al showed similar effectiveness of repeat injections in a prospective study of 100 patients undergoing up to five injections of doses ranging from $100 \mathrm{U}$ to $300 \mathrm{U}{ }^{38}$ They showed a significant difference in frequency, urgency, and urgency incontinence when compared with baseline, with differences maintained for each injection. The inter-injection interval averaged 322 days (10.6 months).

These studies can guide providers on how to counsel patients about the expected timeframe of maintenance injections, and can help high-volume prescribers of onabotulinumtoxinA injections set up a system to anticipate the needs of those patients undergoing multiple repeat injections. A reasonable and efficient method to time repeat injections could be carried out as follows: the patients are counseled that their first repeat injection will be triggered by symptom return, then, when they have had several injections and have a reasonable sense of the therapeutic duration, they are scheduled for repeat injections at a set interval.

In nearly all the reports of ROAB patients, concurrent use of antimuscarinic therapy is a confounding issue in studies of the efficacy and duration of onabotulinumtoxinA. Some investigators required discontinuation of antimuscarinics, some allowed a stable regimen throughout their study, and some allowed for stopping and then restarting antimuscarinic medications. This variability can confuse comparisons of clinical-trial study populations, and can limit our ability to apply the results to the general ROAB patient. More work is needed to enable providers to counsel patients as to whether they will be able to stop antimuscarinic therapies after onabotulinumtoxinA injections, which would be highly desirable for many patients. 
Currently, the package insert for onabotulinumtoxinA suggests that when treating adult patients for one or more indications, the maximum cumulative dose in a 3-month interval should generally not exceed 360 U. High cumulative doses are probably more common in the neuropathic population, but $\mathrm{OAB}$ patients should be asked if they are receiving onabotulinumtoxinA for other indications prior to injection. Concerns about the development of treatment resistance and the role of antibody formation are being investigated, as botulinum toxins are proteins derived from bacteria and are capable of generating an immune response.

Naumann et al reported the results of a meta-analysis of five studies of antibody conversion in patients in clinical trials of onabotulinumtoxinA lasting from 4 months to 2 years with 1-15 treatments (mean 3.8) for various indications (glabellar lines, cervical dystonia, post-stroke spasticity, axillary hyperhidrosis, neurogenic bladder).$^{39}$ Overall, 11/2,240 (0.49\%) of patients converted from neutralizing antibody negative to positive on post-exposure assay; there were no hypersensitivity or immune-related adverse events. After the positive antibody result, three patients became unresponsive to treatment and seven remained responsive. A different detection method was used in a series of 17 children with neurogenic bladder. ${ }^{40}$ Antibodies were detected in $35 \%$, and this population also suffered from a very high failure rate - nine of 17 patients overall. The authors determined that other causes for failure were likely in all but 12\%; however, it would be difficult to make generalizations from this population. Denys et al reported prospectively on antibody formation in the previously mentioned dose-ranging study and found only two of 99 patients had formed antibodies when tested at 6 months post-injection, and this did not impact efficacy. ${ }^{24}$

In patients with apparent resistance to injection, providers can consider technical problems with the toxin preparation or injection, antibody testing, or simple test injection of a small dose of toxin into facial muscles (frontalis or unilateral brow injection) to allow for confirmation of clinical response.

\section{Long-term use}

The long-term use of onabotulinumtoxin $\mathrm{A}$ for $\mathrm{OAB}$ is another area of ongoing research, and it will take several more years of routine use to accumulate enough data to determine 10-, $15-$, or 20-year outcomes. There is concern about loss of efficacy over time, as well as patient adherence to onabotulinumtoxinA injection regimens for either clinical or practical reasons. Long-term use appears to be safe in studies up to 7 years of follow-up. ${ }^{41}$

The use of onabotulinumtoxinA administration in female patients who are pregnant, considering becoming pregnant, or are breastfeeding also requires consideration. Use of onabotulinumtoxin $\mathrm{A}$ is pregnancy category $\mathrm{C}$, and it is unknown whether it is excreted in breast milk. It is prudent to administer point-of-care pregnancy testing in those female patients of childbearing age prior to exposing them to onabotulinumtoxinA and to avoid its use in pregnant and breastfeeding women.

\section{Complications and their management}

The most common complications after onabotulinumtoxinA injection are urinary retention and UTI. Urinary retention requiring CIC and elevated PVRs are dose dependent, with retention occurring in $6.3 \%(5 \%-11 \%)$ of women after $100 \mathrm{U}$, $16.9 \%(6.7 \%-21.2 \%)$ after $200 \mathrm{U}$, and $16.4 \%$ after $300 \mathrm{U}$ (summarized in Table 3). Retention requiring CIC was defined in many studies as an inability to void or a residual above $150-200$ cc causing urinary symptoms, which is a good clinical principle to follow, since there is to date no good evidence that elevated PVRs alone are harmful. PVRs can also increase with onabotulinumtoxinA injection dose and residuals over $200 \mathrm{~mL}$ occur in $7 \%-8 \%$ after $100 \mathrm{U}$ or $200 \mathrm{U}^{35-37,41,42}$

Onset of urinary retention typically coincides with the clinical efficacy beginning, at between 5 and 10 days after injection..$^{35-37,41,42}$ The duration of retention is variable, with some patients only requiring CIC for a few days, while for others, the condition persists for the duration of the effects of the drug. Visco et al monitored retention duration in a group of women receiving $100 \mathrm{U}$ of Botox and noted $5 \%$ of women in retention at 2 months, $3 \%$ at 4 months and $1 \%$ at 6 months. ${ }^{43}$

Patients often ask about their risk of retention with subsequent injections, and, thankfully, retention complications tend to be stable over multiple injections: of those patients having no retention with their first injection, $87 \%$ were able to void after their second, ${ }^{35,38}$ whereas, of those patients who developed retention after one injection, $100 \%$ required catheterization with their second..$^{35,36}$

Aside from dose of toxin, the risk factors predisposing a person to retention have not been well studied. In a nonrandomized trial with 217 men and women receiving injections of 100-200 U into the detrusor body only or into bladder base and trigone, ${ }^{42}$ significant independent risk factors for urinary retention were: male sex (odds ratio [OR] 9.2), age older than 75 (OR 2.1), and a baseline PVR $>100 \mathrm{cc}$ (OR 9.9). No patients with bladder base/trigone injections developed urinary retention. Sahai et al evaluated preoperative urodynamic parameters as a predictor for the need for CIC after Botox ${ }^{44}$ Pre-treatment slower urine flow (mean $15 \mathrm{vs} 22 \mathrm{~mL} / \mathrm{sec}$ ), lower projected isovolumetric pressure 


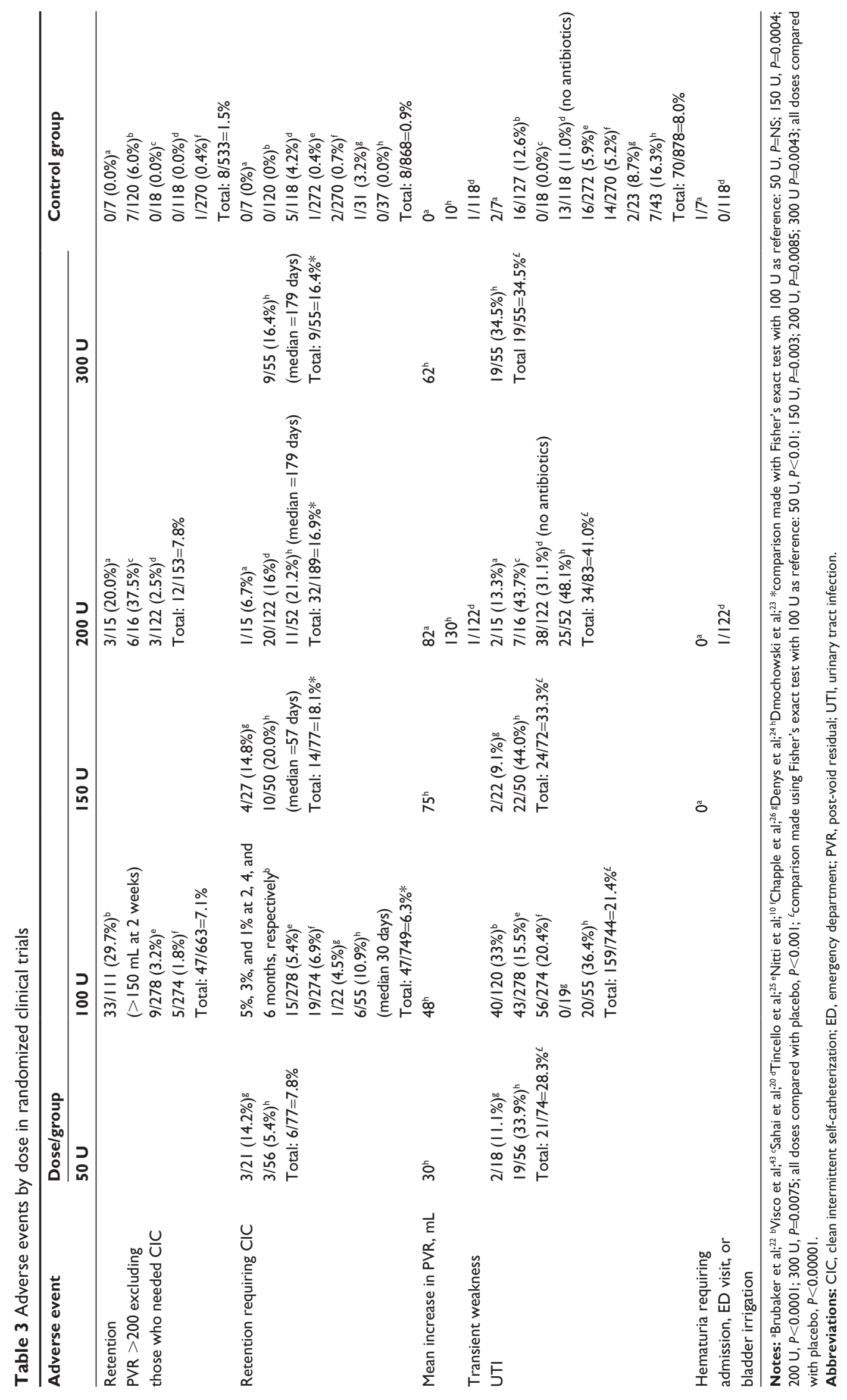


in women, and lower bladder contractility index, were significantly associated with the need for CIC. In a small series with 44 patients, attempts to prevent urinary retention by injecting the external sphincter along with the bladder at the time of the bladder injection decreased PVR by $50 \mathrm{cc}$ at 4 weeks but made no difference to PVR at 3 months and did not change the incidence of urinary retention; as such, this technique has not been further pursued. ${ }^{45}$

The elderly and frail elderly are frequently excluded from medical trials; however, given the natural history of $\mathrm{OAB}$ increasing with age and the high prevalence of antimuscarinic intolerance in this population, the elderly are in great need of this therapy. In a consecutive series of the elderly, patients aged over 65, incidence of and elevated PVR of $>150 \mathrm{~mL}$ was significantly higher in the frail elderly $(60.7 \%)$ than in the other groups (39.7\% and $35.7 \%$, respectively). The rate of Acute urinary retention showed a trend toward the greatest incidence in the frail elderly. ${ }^{46}$ In another study of 21 patients aged $>75$ there were no cases of elevated PVR or urinary retention. ${ }^{28}$

The incidence of retention at higher doses prompted the FDA to approve the $100 \mathrm{U}$ dose for non-neurogenic OAB, and this is the recommended dose to maximize efficacy while minimizing side effects. Additional caution should be observed in male patients and the frail elderly. It is unclear if routine urodynamics could be used before Botox injections to predict retention. Ideally, all patients should be taught, or at least introduced to, the concept of self-catheterization before the procedure. Post-procedure instructions on recognizing retention should be reinforced, since the presentation is not always an inability to void. In some patients, retention presents insidiously as worsening incontinence and urgency.

UTIs are common after any endoscopic procedure, and occurred in an average of $8.0 \%(5 \%-15 \%)$ of the randomized trial subjects receiving placebo injections of saline. With the high prevalence of elevated residuals after injection of onabotulinumtoxinA, UTIs are much more common, occurring in $21.4 \%$ after $100 \mathrm{U}$ and higher rates (33.3\%-41.0\%) corresponding to higher doses. In those studies in which routine antibiotics were not given, the rates of infection were at the higher ends of these ranges.

Systemically, transient weakness from onabotulinumtoxinA diffusion can occur with any injection location but seems to be a rare event in the bladder. It was not reported in any of the RCTs except for the RELAX trial, in which it occurred in 1/122 patients who received onabotulinumtoxinA and $1 / 118$ patients who received placebo. ${ }^{25}$ However, in a nonrandomized trial, it was noted in $2.8 \%$ of injections. ${ }^{42}$ Given the injection technique, mild hematuria is expected transiently after the procedure, but severe hematuria requiring intervention or hospitalization for bladder irrigation occurs infrequently ( $\sim 1 \%$ in RCTs).

Not all patients have treatment success, and, outside of clinical trials, many patients discontinue injections primarily due to lack of efficacy or intolerable side effects, including need for catheterization. ${ }^{38,41}$ In a series with 268 patients in a real-world setting, at 3 years, $61.3 \%$ of patients had discontinued injections for these same reasons. ${ }^{41}$

There are few studies on the success of alternative therapies with SNM or percutaneous tibial nerve stimulation after onabotulinumtoxinA failure. In a series of 20 patients who had failed onabotulinumtoxinA injections ( $85 \%$ due to lack of efficacy), 70\% had a successful first-stage SNM, and, 1 year after implant, $79 \%$ were satisfied with the treatment. ${ }^{47}$ Other authors have not noted such high success rates. ${ }^{48}$

Suprapubic or urethral indwelling catheters are often inappropriately used to manage intractable urgency incontinence. These carry high risk of infection, urethral destruction, and bladder stones and are not recommended since diapering or pads is a safer option. Only in rare instances when decubitus ulcers form as a result of incontinence should a catheter be considered. ${ }^{6}$

Augmentation cystoplasty is a major surgical procedure offered as a last resort treatment for patients with refractory OAB ${ }^{6}$ Drawbacks to this technique include high risk of permanent urinary retention and long-term risk of malignancy. ${ }^{49}$ With the relatively recent FDA approval of onabotulinumtoxinA, there are no studies, as far as we are aware, that address specifically the success of augmentation cystoplasty after failed botulinum toxin injection. Urinary diversion is typically reserved for the most complex patients, usually in the event that the outlet is not salvageable or self-catheterization not possible.

\section{Conclusion}

Short- and medium-term data are very robust for onabotulinumtoxin A as a safe and effective treatment for ROAB. As it is rapidly being adopted into clinical practice, outcomes of longer-term, real-world applications of this treatment will be forthcoming.

\section{Disclosure}

The authors declare no conflicts of interest in this work.

\section{References}

1. Haylen BT, Freeman RM, Swift SE, et al. An international urogynecological association (IUGA)/international continence society (ICS) joint terminology and classification of the complications related directly to the insertion of prostheses (meshes, implants, tapes) and grafts in female pelvic floor surgery. Neurourol Urodyn. 2011;30(1):2-12. 
2. Stewart WF, Van Rooyen JB, Cundiff GW, et al. Prevalence and burden of overactive bladder in the United States. World J Urol. 2003;20(6): 327-336.

3. Hashim H, Abrams P. Drug treatment of overactive bladder: efficacy, cost and quality-of-life considerations. Drugs. 2004;64(15):1643-1656.

4. Andersson KE, Fullhase C, Soler R. Urothelial effects of oral agents for overactive bladder. Curr Urol Rep. 2008;9(6):459-464.

5. Cameron AP, Jimbo M, Heidelbaugh JJ. Diagnosis and office-based treatment of urinary incontinence in adults. Part two: treatment. Ther Adv Urol. 2013;5(4):189-200.

6. Gormley EA, Lightner DJ, Burgio KL, et al; American Urological Association; Society of Urodynamics, Female Pelvic Medicine and Urogenital Reconstruction. Diagnosis and treatment of overactive bladder (non-neurogenic) in adults: AUA/SUFU guideline. J Urol. 2012;188(Suppl 6):2455-2463.

7. Madhuvrata P, Cody JD, Ellis G, Herbison GP, Hay-Smith EJ. Which anticholinergic drug for overactive bladder symptoms in adults. Cochrane Database Syst Rev. 2012;1:CD005429.

8. Veenboer PW, Bosch JL. Long-term adherence to antimuscarinic therapy in everyday practice: a systematic review. J Urol. 2013;191(4): 1003-1008.

9. Benner JS, Nichol MB, Rovner ES, et al. Patient-reported reasons for discontinuing overactive bladder medication. BJU Int. 2010;105(9): 1276-1282.

10. Nitti VW, Auerbach S, Martin N, Calhoun A, Lee M, Herschorn S. Results of a randomized phase III trial of mirabegron in patients with overactive bladder. J Urol. 2013;189(4):1388-1395.

11. Phé V, de Wachter S, Rouprêt M, Chartier-Kastler E. How to define a refractory idiopathic overactive bladder? Neurourol Urodyn. Epub October 24, 2013.

12. Al-zahrani AA, Elzayat EA, Gajewski JB. Long-term outcome and surgical interventions after sacral neuromodulation implant for lower urinary tract symptoms: 14-year experience at 1 center. J Urol. 2011;185(3):981-986.

13. Gaziev G, Topazio L, Iacovelli V, et al. Percutaneous tibial nerve stimulation (PTNS) efficacy in the treatment of lower urinary tract dysfunctions: a systematic review. BMC Urol. 2013;13:61.

14. Chapple CR. Which preparation of botulinum toxin a should be used, where should it be injected, and how should its efficacy be assessed? Eur Urol. 2012;61(5):936-937; discussion 938.

15. Ravindra P, Jackson BL, Parkinson RJ. Botulinum toxin type A for the treatment of non-neurogenic overactive bladder: does using onabotulinumtoxinA (Botox $\left({ }^{\circledR}\right)$ ) or abobotulinumtoxinA (Dysport $\left({ }^{\circledR}\right)$ ) make a difference? BJU Int. 2013;112(1):94-99.

16. Andersson KE. New developments in the management of overactive bladder: focus on mirabegron and onabotulinumtoxinA. Ther Clin Risk Manag. 2013;9:161-170.

17. Giannantoni A, Conte A, Farfariello V, et al. Onabotulinumtoxin-A intradetrusorial injections modulate bladder expression of NGF, TrkA, p75 and TRPV1 in patients with detrusor overactivity. Pharmacol Res. 2013;68(1):118-124.

18. Collins VM, Daly DM, Liaskos M, et al. OnabotulinumtoxinA significantly attenuates bladder afferent nerve firing and inhibits ATP release from the urothelium. BJU Int. 2013;112(7):1018-1026.

19. Flynn MK, Amundsen CL, Perevich M, Liu F, Webster GD. Outcome of a randomized, double-blind, placebo controlled trial of botulinum A toxin for refractory overactive bladder. J Urol. 2009;181(6):2608-2615.

20. Sahai A, Khan MS, Dasgupta P. Efficacy of botulinum toxin-A for treating idiopathic detrusor overactivity: results from a single center, randomized, double-blind, placebo controlled trial. J Urol. 2007;177(6): 2231-2236.

21. Kalsi V, Apostolidis A, Gonzales G, Elneil S, Dasgupta P, Fowler CJ. Early effect on the overactive bladder symptoms following botulinum neurotoxin type A injections for detrusor overactivity. Eur Urol. 2008;54(1):181-187.

22. Brubaker L, Richter HE, Visco A, et al; Pelvic Floor Disorders Network. Refractory idiopathic urge urinary incontinence and botulinum A injection. J Urol. 2008;180(1):217-222.
23. Dmochowski R, Chapple C, Nitti VW, et al. Efficacy and safety of onabotulinumtoxinA for idiopathic overactive bladder: a double-blind, placebo controlled, randomized, dose ranging trial. J Urol. 2010;184(6): 2416-2422.

24. Denys P, Le Normand L, Ghout I, et al; VESITOX study group in France. Efficacy and safety of low doses of onabotulinumtoxinA for the treatment of refractory idiopathic overactive bladder: a multicentre, double-blind, randomised, placebo-controlled dose-ranging study. Eur Urol. 2012;61(3):520-529.

25. Tincello DG, Kenyon S, Abrams KR, et al. Botulinum toxin a versus placebo for refractory detrusor overactivity in women: a randomised blinded placebo-controlled trial of 240 women (the RELAX study). Eur Urol. 2012;62(3):507-514.

26. Chapple C, Sievert KD, MacDiarmid S, et al. OnabotulinumtoxinA $100 \mathrm{U}$ significantly improves all idiopathic overactive bladder symptoms and quality of life in patients with overactive bladder and urinary incontinence: a randomised, double-blind, placebo-controlled trial. Eur Urol. 2013;64(2):249-256.

27. Nitti VW, Dmochowski R, Herschorn S, et al; EMBARK Study Group. OnabotulinumtoxinA for the treatment of patients with overactive bladder and urinary incontinence: results of a phase 3, randomized, placebo controlled trial. J Urol. 2013;189(6):2186-2193.

28. White WM, Pickens RB, Doggweiler R, Klein FA. Short-term efficacy of botulinum toxin a for refractory overactive bladder in the elderly population. J Urol. 2008;180(6):2522-2526.

29. Kuo H. Reduction of urgency severity is associated with long-term therapeutic effect after intravesical onabotulinumtoxin A injection for idiopathic detrusor overactivity. Neurourol Urodyn. 2011;30(8): 1497-1502.

30. Makovey I, Davis T, Guralnick ML, O’Connor RC. Botulinum toxin outcomes for idiopathic overactive bladder stratified by indication: lack of anticholinergic efficacy versus intolerability. 2011;30(8):1538-1540.

31. Wolf JS Jr, Bennett CJ, Dmochowski RR, Hollenbeck BK, Pearle MS, Schaeffer AJ; Urologic Surgery Antimicrobial Prophylaxis Best Practice Policy Panel. Best practice policy statement on urologic surgery antimicrobial prophylaxis. J Urol. 2008;179(4):1379-1390.

32. Kuo H. Bladder base/trigone injection is safe and as effective as bladder body injection of onabotulinumtoxinA for idiopathic detrusor overactivity refractory to antimuscarinics. Neurourol Urodyn. 2011;30(7):1242-1248.

33. Altaweel W, Mokhtar A, Rabah DM. Prospective randomized trial of $100 \mathrm{u}$ vs $200 \mathrm{u}$ botox in the treatment of idiopathic overactive bladder. Urol Ann. 2011;3(2):66-70.

34. Sahai A, Dowson C, Khan MS, Dasgupta P; GKT Botulinum Study Group. Repeated injections of botulinum toxin-A for idiopathic detrusor overactivity. Urology. 2010;75(3):552-558.

35. Khan S, Kessler TM, Apostolidis A, et al. What a patient with refractory idiopathic detrusor overactivity should know about botulinum neurotoxin type a injection. J Urol. 2009;181(4):1773-1778.

36. Granese R, Adile G, Gugliotta G, Cucinella G, Saitta S, Adile B. Botox $\left({ }^{\circledR}\right)$ for idiopathic overactive bladder: efficacy, duration and safety. Effectiveness of subsequent injection. Arch Gynecol Obstet. 2012;286(4):923-929.

37. Gamé X, Khan S, Panicker JN, et al. Comparison of the impact on health-related quality of life of repeated detrusor injections of botulinum toxin in patients with idiopathic or neurogenic detrusor overactivity. BJU Int. 2011;107(11):1786-1792.

38. Dowson C, Watkins J, Khan MS, Dasgupta P, Sahai A. Repeated botulinum toxin type A injections for refractory overactive bladder: medium-term outcomes, safety profile, and discontinuation rates. Eur Urol. 2012;61(4):834-839.

39. Naumann M, Carruthers A, Carruthers J, et al. Meta-analysis of neutralizing antibody conversion with onabotulinumtoxinA (BOTOX $\left.{ }^{\circledR}\right)$ across multiple indications. Mov Disord. 2010;25(13):2211-2218.

40. Schulte-Baukloh H, Herholz J, Bigalke H, Miller K, Knispel HH. Results of a BoNT/A antibody study in children and adolescents after onabotulinumtoxin A (Botox ${ }^{\circledR}$ ) detrusor injection. Urol Int. 2011;87(4): 434-438. 
41. Mohee A, Khan A, Harris N, Eardley I. Long-term outcome of the use of intravesical botulinum toxin for the treatment of overactive bladder (OAB). BJU Int. 2013;111(1):106-113.

42. Kuo HC, Liao CH, Chung SD. Adverse events of intravesical botulinum toxin a injections for idiopathic detrusor overactivity: risk factors and influence on treatment outcome. Eur Urol. 2010;58(6):919-926.

43. Visco AG, Brubaker L, Richter HE, et al; Pelvic Floor Disorders Network. Anticholinergic therapy vs onabotulinumtoxina for urgency urinary incontinence. N Engl J Med. 2012;367(19):1803-1813.

44. Sahai A, Khan MS, Le Gall N, Dasgupta P; GKT Botulinum Study Group. Urodynamic assessment of poor responders after botulinum toxin-A treatment for overactive bladder. Urology. 2008;71(3):455-459.

45. Schulte-Baukloh H, Weiss C, Stolze T, et al. Botulinum-A toxin detrusor and sphincter injection in treatment of overactive bladder syndrome: objective outcome and patient satisfaction. Eur Urol. 2005;48(6): 984-990; discussion 990.
46. Liao $\mathrm{CH}$, Kuo HC. Increased risk of large post-void residual urine and decreased long-term success rate after intravesical onabotulinumtoxinA injection for refractory idiopathic detrusor overactivity. J Urol. 2013;189(5):1804-1810.

47. Smits MA, Oerlemans D, Marcelissen TA, Van Kerrebroeck PE, De Wachter SG. Sacral neuromodulation in patients with idiopathic overactive bladder after initial botulinum toxin therapy. $J$ Urol. 2013;190(6):2148-2152.

48. Lenherr SM, Morhardt D, Crossley H, et al. Analysis of cross-over rates between sacral neuromodulation and onabotulinumtoxinA injection in refractory idiopathic overactive bladder. In: Society of Urodynamics, Female Pelvic Medicine and Urogenital Reconstruction 2014 Winter Meeting February 25-March 1, 2014 Doral Golf Resort and Spa Miami, Florida. Neurourology and Urodynamics. 2014;33(2):162-266.

49. Reyblat P, Ginsberg DA. Augmentation enterocystoplasty in overactive bladder: is there still a role? Curr Urol Rep. 2010;11(6):432-439.
Research and Reports in Urology

\section{Publish your work in this journal}

Research and Reports in Urology is an international, peer-reviewed, open access journal publishing original research, reports, editorials, reviews and commentaries on all aspects of adult and pediatric urology in the clinic and laboratory including the following topics: Pathology, pathophysiology of urological disease; Investigation and treatment of

\section{Dovepress}

urological disease; Pharmacology of drugs used for the treatment of urological disease. The manuscript management system is completely online and includes a very quick and fair peer-review system, which is all easy to use. Visit http://www.dovepress.com/testimonials.php to read real quotes from published authors.

Submit your manuscript here: http://www.dovepress.com/research-and-reports-in-urology-journal 